\title{
POLÍTICA EXTERNA BOLIVARIANA: A INSERÇÃO INTERNACIONAL DA VENEZUELA AO LONGO DOS DOIS PRIMEIROS MANDATOS DE HUGO CHÁVEZ FRÍAS (1999-2007)
}

\author{
Pedro Henrique de Moraes Cicero ${ }^{1}$
}

\section{Introdução: Bases, objetivos e periodização da Política Exter- na Bolivariana}

De acordo com Romero (2006), a política externa firmada ao longo da administração de Hugo Chávez caracterizou-se, entre outras dimensões, pelo uso não exclusivamente comercial dos hidrocarbonetos para a projeção internacional do país. Segundo o autor, tal característica colocou a assim denominada "diplomacia bolivariana ${ }^{2 "}$ na contramão dos governos venezuelanos que a precederam, na medida em que, desde seus primórdios e a partir da referida especificidade, a proposta buscou a contraposição frente ao status quo estabelecido nos âmbitos regional e internacional.

Nesse sentido, o entendimento inicialmente assumido pelo governo bolivariano sobre a política internacional centrou-se na denúncia e no combate à [má] distribuição mundial do poder. Este posicionamento já aparecia em diversos documentos do momento anterior à vitória eleitoral, nos quais

\footnotetext{
I Coordenador do curso de Relações Internacionais na Universidade Federal de Uberlândia (20I5-20I7), Professor Adjunto na Universidade Federal de Uberlândia, Doutor e Mestre em Ciência Política pela Universidade Estadual de Campinas(UNICAMP). E-mail: pedrohenrique@ufu.br

2 "Diplomacia Bolivariana" e "Política Externa Bolivariana" são as designações comumente utilizadas (Romero, 2006; Jácome, 20II) para fazer referência às ações internacionais firmadas pelo governo venezuelano a partir da eleição de Hugo Chávez, em I999. Nesse sentido, incorpora-se esta dimensão internacional ao projeto político estabelecido internamente, o qual foi denominado "Revolução Bolivariana”.
} 
o grupo político liderado por Chávez imputava parcela da culpa pelo subdesenvolvimento venezuelano às chamadas "nações poderosas3". Assim, ao assumir a presidência, Chávez passou a orientar a política externa venezuelana preponderantemente pautado na luta pelo fortalecimento da multipolaridade nas Relações Internacionais.

Tal projeto partia do diagnóstico da existência de apenas um polo de poder no Sistema Internacional (os EUA), o que produzia, por sua vez, um cenário desalentador para as demais nações, pois, diferentemente da bipolaridade experimentada durante a Guerra Fria, não havia contrapesos ao projeto "neoliberalizante e globalizador" disseminado por Washington. Sobre esta problemática, em entrevista concedida à revista Foreign Affairs, Chávez afirmou:

Hay que luchar contra un mundo unipolar y a favor de un nuevo orden internacional del que se viene hablando desde hace ya décadas, pero que se ha quedado en el discurso. Una política internacional justa, democrática, equilibrada resulta indispensable. Pero para lograrlo hay que contribuir a la creación de ese mundo pluripolar4.

Norteado pelo referido diagnóstico, as ações iniciais da Política Externa Bolivariana (PEB) se propuseram a contribuir para a articulação de polos de poder alternativos à institucionalidade internacional erigida a partir da hegemonia estadunidense. Chávez e seus correligionários anunciavam, pois, seu comprometimento com os ideais de solidariedade e de unidade latino-americana expressados por Simón Bolívar em meados do século XIX, os quais foram recuperados e fundidos à situação de interdependência entre as nações no Sistema Internacional contemporâneo. O presidente venezuelano estava, portanto, convencido de que para vencer a dependência e o subdesenvolvimento era imprescindível construir um projeto e uma estratégia coletiva entre seus pares latino-americanos (Lander 2005).

Entretanto, tais princípios, por si só, não teriam significado se não fossem colocados em prática por meio de experiências concretas. Estas, por sua vez, estavam atreladas à conjuntura política doméstica, a qual influenciou e pautou os compromissos externos de um governo que, desde o início, se mostrou diplomaticamente ativo. Partindo-se, então, desta interface, este

3 Tal como aparece, por exemplo, na seção sobre conjuntura internacional exposta no documento intitulado "Agenda Alternativa Bolivariana", o qual foi publicado pelo Movimiento Bolivariano Revolucionário-200 em I996, e que pode ser acessado, na íntegra, em: http://www. imprentanacional.gob.ve/web/libros/libros/Libro-Rojo-II-2-I4-fs-web.pdf.

4 A entrevista, cujo título é "Globalización: La enfermedad del nuevo milenio", pode ser acessada em: http://www.foreignaffairs-esp.org. 
artigo pretende enfatizar as articulações presentes entre os dois níveis - interno e internacional - como elemento crucial para a construção argumentativa acerca das potencialidades e debilidades apresentadas pela diplomacia bolivariana em seu intento de, efetivamente, contribuir para o estabelecimento de práticas modificadoras do status quo no contexto das relações internacionais contemporâneas

Em linhas gerais, a atuação da diplomacia venezuelana durante os dois primeiros mandatos presidenciais cumpridos por Hugo Chávez Frías foi marcada por dois interstícios nos quais se adotou uma postura proativa e, até certo ponto, audaciosa, entremeados por um período em que a conturbada conjuntura doméstica freou acentuadamente seu "ímpeto internacionalista". Pautado no estudo pormenorizado desses três momentos, este texto vislumbra caracterizar e problematizar as mais relevantes ações e fundamentos incorporados pelos bolivarianos no contexto da política internacional.

\section{A primeira ofensiva diplomática (1999-2001)}

O primeiro momento de destacada atuação por parte da Diplomacia Bolivariana transcorreu entre I999 e 200I, tendo sido caracterizado pela combinação de um discurso agressivo e contundente que, na prática, restou diluído pela implementação de projetos e iniciativas mais moderadas. Inicialmente, a PEB teve de acompanhar e se inserir no amplo programa de reconfigurações institucionais propostas pelo novo mandatário ao país. Assim, em consonância com o esforço inicial pela articulação de um processo constituinte5, o qual vislumbrava a "refundação da República", a postura adotada pelo novo governo em relação à política exterior anteriormente estabelecida também se pautou pela crítica e, conseqüentemente, pela necessidade de alterações substanciais.

Para tanto, José Vicente Rangel, o primeiro chanceler bolivariano, centrou suas intervenções e discursos na argumentação segundo a qual a política exterior do passado não respondia aos interesses do povo venezuelano por ser demasiadamente elitista. Acrescentava, ainda, que a eleição de Chávez demonstrava de maneira inequívoca o anseio por mudanças drásticas na política nacional, as quais, naturalmente, também deveriam ser estendidas

5 A principal bandeira política de Chávez durante a campanha eleitoral de I998 expressava a necessidade da completa reformulação das instituições políticas venezuelanas. Para tanto, propunha-se o estabelecimento de um processo constituinte, o qual, através de plebiscito, foi aquiescido pela população, já em I999. Num contexto no qual I2I das I3I constituintes eram correligionários de Chávez, a nova Carta Magna do país, promulgada em I5 de dezembro de I999, espelhou, em grande medida, o programa de governo apresentado pelo líder bolivariano. 
ao manejo da política internacional. Daí, então, a imperiosidade de se colocar em prática uma diplomacia inovadora, eminentemente soberana e solidária que fosse reflexo fiel das transformações firmadas nas estruturas internas da nação em benefício dos setores populares (Boersner 2009).

Destarte, nesse momento inicial, e em linhas gerais, o governo bolivariano se esforçou para articular e liderar o grupo de países latino-americanos empenhados em pressionar pelo estabelecimento de relações e organizações internacionais centradas nos princípios da equidade e da solidariedade, as quais, conseqüentemente, ajudariam a construir um cenário de maior justiça social na região. Chávez despontou, pois, como esteio dos demais governantes que compunham a chamada "nova esquerda" latino-americana ${ }^{6}$ que ascendeu ao poder nos anos iniciais do novo milênio com plataformas críticas ao paradigma de globalização neoliberal.

Nesse sentido, e tendo em vista o perfil avesso [ou não] aos princípios neoliberais, Chávez deliberadamente aproximou sua diplomacia dos governos latino-americanos que considerava "progressistas"; por sua vez, passou a evitar alianças com os países que, para o mandatário bolivariano, eram administrados por "oligárquicas" e, por isso, se comportavam como prepostos estadunidenses no cenário regional. Tal postura resultou, num primeiro momento, no enfraquecimento das relações bilaterais com a Colômbia e com o México, dada suas posições permissivas e conciliatórias ante os interesses estadunidenses para a região. Em contrapartida, notou-se uma acentuada aproximação diplomática em relação a Cuba (Boersner 2009).

Por sua vez, no que se refere às relações econômicas internacionais e, especialmente, à política petroleira e comercial firmada durante os três primeiros anos da administração bolivariana, emergiram duas estratégias centrais: o empenho em fortalecer a Organização dos Países Exportadores de Petróleo (OPEP) e, também, o esforço com vistas a diversificar os parceiros e a abrangência do comércio exterior venezuelano. Ambas as estratégias tinham como motivação comum a luta para amainar a dependência econômica do país em relação às exportações para os Estados Unidos, de modo que o corpo diplomático foi mobilizado para articular parcerias com novos consortes comerciais ao redor do mundo, bem como para fortalecer os vínculos já existentes.

O mandatário venezuelano e seus mais destacados assessores se

6 A eleição de Chávez em 1998 foi a primeira de uma série de vitórias de candidatos considerados "anti-neoliberais" no cenário político latino-americano da virada do milênio. Em que pesem as especificidades de cada um desses governos, havia entre eles importantes similitudes no que concernia, por exemplo, à necessidade de se firmar uma "contra-agenda", pautada nas lutas pela soberania estatal, pela solidariedade internacional e pela viabilização de mecanismos coletivos que auxiliassem no desenvolvimento endógeno dessas nações (Miranda, 20I2). 
mostraram, pois, firmemente comprometidos em trabalhar no seio do cartel petroleiro com vistas a rearticulá-lo e, com isso, consolidar a força política necessária para empreender ações mais sistemáticas em relação à precificação do combustível no mercado internacional. Para além do aumento dos preços - objetivo de suma importância, tendo em vista a característica rentista da economia venezuelana (Cicero 2015) - a luta pela rearticulação da OPEP também se firmava como uma oportunidade para a PEB apresentar seu "cartão de visitas" no sentido de incorporar esforços com vistas a fortalecer a multipolaridade no Sistema Internacional.

Mesmo frente à heterogeneidade política dos participantes do cartel ${ }^{7}$ Chávez e o aparelho diplomático venezuelano obtiveram sucesso em seu intento e, entre 27 e 28 de setembro de 2000 , Caracas sediou a II Cúpula da OPEP. Naquela ocasião, a maioria dos países-membros se fez representar por seus chefes de Estado ou por membros do alto-escalão burocrático. O documento resultante da conferência - a "Declaração de Caracas" - elencou os acordos firmados entre os países exportadores de petróleo, os quais, entre outras deliberações, se comprometiam a cumprir a política de preços estáveis ${ }^{8}$, a agregar o imposto sobre produtos industrializados como um componente essencial para a definição do preço final de venda dos barris e, também, a estreitar os vínculos institucionais do cartel.

Por sua vez, no que se refere especificamente ao esforço pela diversificação dos parceiros comercias venezuelanos, os resultados obtidos foram conflitantes. Por um lado, as exportações petroleiras continuaram sendo direcionadas, em grande medida, para os mercados tradicionais, sobretudo para o estadunidense. Por certo, a manutenção do fornecimento do combustível em níveis similares aos registrados no período imediatamente anterior à posse de Chávez constituiu um elemento fundamental para a postura complacente adotada num primeiro momento por Washington diante dos discursos proferidos pelo mandatário venezuelano (Illera 2005).

Entretanto, em que pese à mencionada estabilidade dos fluxos comerciais ante os EUA, algumas ações diplomáticas foram concretizadas com o

7 Entre os membros da OPEP se encontra a Arábia Saudita, cuja família real historicamente assume uma posição conservadora e avessa a eventos que possam servir de palco para discursos potencialmente perturbadores do status quo internacional.

8 A proposta apresentada pelos venezuelanos durante a Cúpula e aceita pelos demais membros da OPEP acenava para a manutenção do preço do barril de petróleo no patamar ente US\$ 22 e US\$28. A estratégia comercial para lograr tal estabilidade era pautada no seguinte mecanismo: caso o valor do combustível excedesse o limite dos 28 dólares por mais de 20 dias úteis, os países do cartel injetariam mais 500 milhões de barris por dia no mercado mundial; por sua vez, caso o preço ficasse abaixo do valor mínimo estabelecido, adotar-se-ia a medida inversa (Arriagada, 2005). 
intuito de reorientar geograficamente não apenas as exportações petrolíferas do país caribenho como, também, os intercâmbios comerciais em atividades econômicas não-rentistas. Já nesse momento, a China emergiu como a nação com maior potencial para firmar, na prática, o adensamento das relações com consortes, até então, não tradicionais. No mesmo sentido, a PEB instituiu múltiplas ações com vistas a intensificar as relações comerciais com a Europa e, a partir delas, substituir a importação de insumos industriais estadunidenses por bens de capital procedentes do "velho mundo". O governo venezuelano também se comprometeu a conferir condições tributárias e fiscais mais vantajosas a empresas europeias que quisessem estabelecer negócios no país sul-americano. Essa diferença de tratamento foi responsável pela queda significativa dos investimentos estadunidenses no país. Em contrapartida, entre I999 e 2002, os investimentos franceses na Venezuela sextuplicaram. No mesmo período, triplicaram-se o volume de negócios realizados no país por empresas suíças e alemãs (Hidalgo 2009).

Tendo, portanto, obtido êxitos em seus dois objetivos iniciais relativos à política externa - o fortalecimento da OPEP e a diversificação dos parceiros comerciais do país - o governo bolivariano angariou forças para, ainda em 200I, marcar posição em sua estratégia vislumbrando o adensamento da multipolaridade no Sistema Internacional ao não respaldar a proposta da área de livre-comércio hemisférico (ALCA) apresentada pelo governo estadunidense.

O referido posicionamento foi firmado durante a "Terceira Reunião de Cúpula das Américas”, realizada em Quebec, na qual a representação diplomática venezuelana pautou sua atuação na defesa de dois pontos centrais, a saber: primeiro, a necessidade de, também nas Relações Internacionais, extrapolar a democracia representativa e, assim, agregar à prática diplomática elementos os quais possibilitariam a participação direta dos cidadãos nos processos decisórios sobre políticas que concernem à soberania de seus países; segundo, a imperiosidade de se opor à urgência demandada por Washington em sua estratégia de consolidar a área de livre-comércio hemisférico já em 2005, prescindindo de estudos e debates amplos sobre os impactos - positivos e negativos - que tal iniciativa traria para a economia dos países latino-americanos. Tais atitudes estão expressas na "Declaração de Quebec 9 ”, na qual a Venezuela "reservou sua posição" em relação à democracia estritamente representativa no âmbito da OEA, bem como ao prazo máximo de dezembro de 2005 para a entrada em vigor do acordo ALCA.

9 O documento final elaborado pelos países participantes do referido encontro pode ser acessado, na íntegra, em http://www.ftaa-alca.org/summits/quebec. 


\section{0 primeiro contratempo (2001-2003)}

Entretanto, a primeira ofensiva diplomática do regime bolivariano foi freada e, em certa medida, interrompida pela séria instabilidade na política interna experimentada entre os segundos semestres de 2001 e de 2003 . A crise institucional ocasionada por conta da atuação incisiva dos grupos e organizações de oposição ao governo Chávez causou, durante esse período, inúmeros danos ao país, os quais também se fizeram sentir nos negócios e nas atividades políticas venezuelanas firmadas internacionalmente (Romero 2010).

Nesse sentido, mais até do que o efêmero golpe de Estado ocorrido em abril de 2002, a articulação do "Paro Petrolero ${ }^{10}$ " foi a ação que representou, ao menos no âmbito da política externa, o maior obstáculo para o país durante aquele conturbado período. Além dos prejuízos comerciais impostos ao país, a drástica diminuição da produção e comercialização do combustível venezuelano por conta da sabotagem nas atividades da PDVSA gerou, também, instabilidade na produção capitalista internacional, pois os países industrializados se viram repentinamente alijados do acesso a uma importante reserva de hidrocarbonetos. Para tornar o cenário ainda mais desalentador para os últimos, a paralisação da produção venezuelana ocorreu concomitantemente a outro momento de grande tensão política - a invasão do Iraque por parte dos Estados Unidos - situação esta que, também, impactou sobremaneira o comércio internacional do petróleo.

Tendo em vista tal conjuntura, a resolução do impasse petroleiro venezuelano foi tomada como uma prioridade pela comunidade internacional, a qual teve participação decisiva durante o processo que logrou por fim ao lock-out. Para tanto, duas lideranças políticas desempenharam um papel fundamental: o ex-presidente estadunidense Jimmy Carter que, logo após ter sido laureado com o Prêmio Nobel da Paz, em dezembro de 2002, se ofereceu para mediar o conflito entre o governo bolivariano e a oposição; por sua vez, Luiz Inácio Lula da Silva - recém-empossado presidente do Brasil - articulou junto aos mandatários do Chile, México, Espanha, Portugal e Estados Unidos a criação do "Grupo de Amigos da Venezuela”, o qual obteve sucesso em apaziguar os embates ao propor a realização de um referendo revogatório como mecanismo para solucionar a controvérsia (Boersner 2009).

Io Os acontecimentos políticos denominados "Paro Petrolero" consistiram na paralisação das atividades laborais e econômicas por parte de uma expressiva parcela da população como forma de expressar seu descontentamento em relação ao governo presidido por Hugo Chávez. A devastação econômica gerada pela paralisação culminou na queda de $27 \%$ do PIB venezuelano durante o primeiro trimestre de 2003 (Vera, 2005). 
A vitória de Chávez no referendo ${ }^{\text {II }}$ coincidiu com a robusta elevação dos preços do petróleo no mercado internacional. Por conseguinte, alavancaram-se também os ingressos fiscais venezuelanos. O novo cenário, internamente, permitiu ao governo bolivariano promover a expansão dos gastos públicos, os quais foram direcionados primordialmente para financiar uma série de programas sociais - as chamadas "Misiones Bolivarianas" - a partir de então edificados (Cicero 20Io).

No âmbito internacional, a elevação no preço do barril de petróleo também proporcionou a retomada da postura proativa por parte do país caribenho, que passou a dispor das condições materiais necessárias para articular ações diplomáticas mais assertivas e diretas. Aqui, atestando novamente a característica rentista do modelo de desenvolvimento econômico praticado na Venezuela, é fundamental enfatizar a importância e o papel de "fiador" exercido pelo petróleo no processo. Foi, sem dúvida, a condição de país exportador de hidrocarbonetos que conferiu grande parte dos recursos necessários para financiar os projetos mais auspiciosos a partir dali implementados. Assim, conforme será detalhado na próxima seção, sem tais aportes provenientes do comércio internacional de hidrocarbonetos os projetos de integração regional propostos pelos PEB e centrados no uso não exclusivamente comercial do petróleo como instrumento de política externa dificilmente teriam saído do papel.

\section{A segunda ofensiva diplomática (2004-2007)}

O período que começa em 2004 e se estende até 2007 é caracterizado pela intensa atuação da PEB no contexto internacional e, em especial, no cenário interamericano. Durante este momento, dadas as excelentes condições econômicas proporcionadas pelo "boom" nos preços petroleiro que caracterizaram os referidos anos, a diplomacia bolivariana logrou tornar mais complexa e multifacetada a inserção internacional do país. A Venezuela, a partir de então, adotou uma postura proativa e determinada a fazer do "desenvolvimento social” uma prioridade na agenda de suas relações internacionais.

As duas principais empreitadas instituídas regionalmente a partir da iniciativa venezuelana neste período - a "Aliança Bolivariana para as Américas" e a sua articulação no setor energético, o projeto "PetroAmerica" - serão detalhadas em seguida com a finalidade de agregar mais uma dimensão à

II Após um conturbado processo de coleta de assinaturas por parte dos partidos e organizações políticas de oposição ao bolivarianismo, em I5 de agosto de 2004 , ocorreu o pleito, sendo que seu resultado final, por uma margem de $58,25 \%$ contra 4I,74\%, favoreceu a Hugo Chávez Frías. 
análise sobre a maneira pela qual a condição de país exportador de petróleo moldou as escolhas e a ação da política externa venezuelana.

\section{ALBA: Integração Regional para além da economia}

Sobre a ALBA, de início, é fundamental pontuar que tal iniciativa foi articulada para tentar romper com a trajetória até então instituída pelos demais projetos de integração latino-americana e caribenha, cujo ápice, naquele momento, se materializava no âmbito das negociações da ALCA. Além de importantes diferenças em relação aos países que a comporiam - incluindo $\mathrm{Cuba}^{\mathrm{I} 2}$ e excluindo os EUA e o Canadá - a ALBA surgiu como alternativa ao modelo de integração comercial hemisférica orquestrado pelos estadunidenses justamente por contrariar a ênfase que aquela proposta atribuía aos pressupostos neoliberais na condução do processo.

Por sua vez, o projeto de integração bolivariano se pauta, preponderantemente, nas lutas contra a pobreza e contra a exclusão social a partir da adoção de estratégias equitativas de cooperação entre as nações. Em linhas gerais, e retomando a argumentação de Villa $(2007,42)$, pode-se dizer que "a Venezuela concebe um processo de integração em bases não só econômicas, mas também profundamente políticas".

Destarte, tendo em vista os princípios e diretrizes a serem exercidos no âmbito da ALBA, propugna-se a construção de um sistema capaz de combater as assimetrias e de catalisar o desenvolvimento endógeno nacional e regional, o qual ajudaria a mitigar as desigualdades sociais latentes no contexto latino-americano. Nesse sentido, extrai-se de seus documentos constitutivos ${ }^{13}$ que os princípios de integração propostos pela iniciativa são a solidariedade, a complementaridade, o financiamento compensatório para atacar as assimetrias e o tratamento diferenciado entre os países de acordo com as circunstâncias.

Para concretizá-los, as ações propostas se concentram em três núcleos

I2 A participação de Cuba no âmbito da ALBA é um bom exemplo para retratar a singularidade da proposta de integração aventada na alternativa bolivariana. Pelos termos do acordo, a ilha caribenha goza de importantes benefícios comerciais proporcionados pelos venezuelanos, os quais, por sua vez, se mostram cientes das dificuldades econômicas enfrentadas por Cuba e, por isso, adotam ações com vistas a socorrer o país vizinho. Em contrapartida à ajuda prestada, a partir de programas desenhados sob os auspícios da ALBA, os cubanos aportam uma notável quantidade de profissionais qualificados designados para atuar especialmente nas áreas de saúde e de educação na Venezuela e nos demais países que se juntaram à iniciativa.

I3 Tais informações constam no documento oficial intitulado "O que é a ALBA", disponível em http://www.alternativabolivariana.org/pdf/alba_mice_en.pdf. 
principais, a saber: aportar financiamento tanto para as atividades comerciais e infra-estruturais quanto para diminuir o comprometimento orçamentário decorrente da importação de energia por parte dos países do bloco; investir diretamente em projetos sociais, em especial nas áreas de saúde e educação; e firmar acordos comerciais não pautados exclusivamente na reciprocidade material/financeira ${ }^{\mathrm{T}}$.

Nesse sentido, mais do que uma contraposição direta aos princípios e mecanismos vislumbrados pela iniciativa de integração regional proposta pelos estadunidenses, a ALBA consubstanciou, também, uma oposição à globalização neoliberal estabelecida no cenário interamericano. Tal assertiva se justifica, pois os retromencionados documentos constitutivos expressamente consideram as relações comerciais assimétricas entre os países desenvolvidos e os em desenvolvimento como um obstáculo central que dificulta sobremaneira a erradicação da pobreza nos últimos. Para corrigir tal situação, a alternativa bolivariana incentiva o tratamento preferencial tanto para as nações quanto para os setores sociais menos privilegiados que delas fazem parte. Tal postura é firmada exatamente pela necessidade de enfrentar as discrepâncias comerciais ocasionadas pela deterioração dos termos de troca, a qual potencializa a situação de pobreza endêmica enfrentada pelos assim denominados "países periféricos".

Consolida-se, através da ALBA, a intenção por parte da PEB de liderar um processo de integração regional pautado no protagonismo das questões relacionadas ao desenvolvimento econômico e à justiça social, bem como na valorização da cultura e das tradições latino-americanas, fundamentalmente a partir da retomada da herança política de Simón Bolívar (Altmann 2009). Tal proposta reverberou com relativo sucesso no contexto regional e, após uma década de sua fundação, a Organização Internacional está composta por oito nações (Antígua e Barbuda, Bolívia, Cuba, Dominica, Equador, Nicarágua, São Vicente e Granadinas, além da própria Venezuela).

Sobre seus membros, é importante ressaltar o baixo nível de industrialização por eles apresentado, situação esta que os faz continuar dependendo, mesmo participando da iniciativa, das exportações de produtos de baixo valor agregado, os quais são transacionados, em sua maioria, com os países

I4 A não-reciprocidade e o comércio compensatório (feito através da troca direta de produtos) são as duas principais formas pelas quais os princípios da troca justa e do tratamento diferenciado são aplicadas no contexto da ALBA. Além disso, os acordos comerciais são negociados caso a caso, permitindo, assim, flexibilidade para sanar dificuldades específicas de acordo com as circunstâncias de cada país. Nesse sentido, por exemplo, Cuba concordou em garantir acesso duty free às importações venezuelanas, além de remover todas as barreiras não tarifárias; a Venezuela, em retorno, eliminou, apenas, as barreiras não tarifárias (Girvan, 2008). 
industrializados. Tal dinâmica é perversa para o avanço concreto da prática contestatória almejada pela ALBA, pois a persistência dos fluxos comerciais desiguais entre países centrais e periféricos traduz-se num dos fatores que mais contribuem para a manutenção da desigualdade nas relações econômicas internacionais.

\section{“Diplomacia do Petróleo” em tempos bolivarianos}

Quanto à materialização das iniciativas firmadas no âmbito da ALBA, cabe destacar, aqui, os esforços liderados pelo aparelho de política externa venezuelano no sentido de se fazer valer do principal ativo econômico do país para, através dele, catalisar o adensamento das relações político-comerciais intrabloco. Repaginava-se, assim, uma estratégia ampla e historicamente utilizada pela nação caribenha para potencializar sua inserção internacional: a chamada "diplomacia do petróleo ${ }^{\mathrm{I5}}$ ".

Especificamente no contexto da ALBA, o referido mecanismo foi consubstanciado através da implementação do "Projeto PetroAmerica", o qual se propõe, em linhas gerais, a promover e aprofundar a integração energética entre os países latino-americanos. Sobre o cenário político hodierno que determina o avanço [ou não] deste processo, considera Fuser (2OII, OI):

Poucas ideias se mostram capazes de mobilizar um apoio tão unânime das lideranças políticas e empresariais sul-americanas quanto à da necessidade de uma maior integração energética entre os países da região [...] A integração energética é apresentada, consensualmente, como uma meta necessária e possível.

Nesse sentido, e beneficiando-se do cenário político acima descrito, a PEB buscou promover a articulação energética regional a fim de, tendo em vista a abundância de recursos dessa natureza disponíveis aos venezuelanos, coordenar e alavancar o suprimento do combustível aos vizinhos, em especial os caribenhos e centro-americanos.

I5 Segundo Poetner (20II, 87), a estratégia de política externa conhecida por "diplomacia do petróleo" pode assumir duas facetas, a saber: "one is the result of applying force and hegemony to control this energy resource [oil]; the other is the sometimes open and arbitrary use of oil wealth to influence events in other countries. The first situation revolves around the creation of domination and subordination between countries through the control of oil resources. A dependence of oil-importing countries can be further reinforced if supplies are sold at preferential prices or term. The second situation focuses on the actual exercise of the power of wealth in order to gain influence and power over other states by acting directly either on their governments or on opposition groups or movements". 
Ao fazê-lo, além de concretizar a venda do petróleo, o governo liderado por Chávez consolidou, também, sua influência política no contexto regional, na medida em que a integração energética, nos moldes propostos, representava um "bom negócio" também para os importadores de petróleo. Assim, a interdependência firmada, em grande medida, por conta do comércio de hidrocarbonetos conferiu as condições necessárias para a PEB assumir, naquele momento, a postura inovadora e combativa que logrou articular, entre outras iniciativas, a própria ALBA, a qual, mesmo com suas flagrantes debilidades, representa uma importante contribuição bolivariana em seu intento de fortalecer a multipolaridade no Sistema Internacional.

Neste contexto, a PetroAmerica representa, por sua vez, a iniciativa pela qual ocorreria a integração energética sob os auspícios da ALBA. De acordo com o exposto no sítio eletrônico da PDVSA, “a PetroAmerica é uma proposta de integração energética dos povos do continente enquadrada na ALBA", a qual está "fundamentada nos princípios da solidariedade e complementaridade dos países no uso justo e democrático dos recursos no desenvolvimento dos povos" e é concebida como um "habilitador geopolítico orientado ao estabelecimento de mecanismos de cooperação e integração, utilizando recursos energéticos das regiões do Caribe, América Central e América do Sul como base para a melhoria socioeconômica dos povos do continente ${ }^{\mathrm{I} "}$.

O conjunto de ações que englobam a PetroAmerica materializam, portanto, parte importante da política petroleira praticada pela PEB, a qual, a partir de uma proposta integracionista, almeja, essencialmente, valorizar os interesses comerciais e políticos dos países latino-americanos no que concerne o controle e soberania sobre seus recursos energéticos. Assim, práticas como, por exemplo, a venda de petróleo por um valor abaixo do preço de mercado e a consolidação de canais de financiamento para países politicamente alinhados tornaram-se os mecanismos utilizados para operacionalizar a "petrodiplomacia bolivariana". Através da aproximação inicial proporcionada pelos acordos efetuados no campo energético, os venezuelanos buscaram congregar aliados para as suas demandas e propostas articuladas no Sistema Internacional, bem como instigaram a criação de novas Organizações Internacionais pautadas em princípios inovadores e avessos à influência estadunidense, sendo a ALBA o exemplo mais bem acabado desse esforço (Cicero 2015).

Na prática, essencialmente, o plano se propõe a promover a integração das empresas energéticas estatais da América Latina e Caribe para, assim,

I6 Tradução livre das diretrizes expostas em http://www.pdvsa.com/index.php?tpl=interface. sp/design/readmenuprinc.tpl.html\&newsid_temas=46. 
instrumentalizar acordos e realizar investimentos conjuntos nas atividades relacionadas à exploração e comercialização de hidrocarbonetos. A proposta confere, nesse sentido, uma acentuada importância estratégica ao setor, vislumbrando, a partir da integração, a sedimentação de uma governança multinível dos recursos energéticos no âmbito hemisférico, de modo a assegurar a atuação coordenada entre os participantes, bem como o planejamento e avaliação dos desafios e necessidades no longo prazo (Jácome 20II).

Para alcançar a efetivação de tais objetivos, apostou-se na sinergia do conhecimento, da capacidade material e da experiência acumulada pelas empresas públicas ao longo de suas trajetórias específicas nas negociações que envolvem a exploração, compra e distribuição de hidrocarbonetos. Sobre a razão de ser da iniciativa complementa Ruiz-Caro (2006, 24):

Los acuerdos enmarcados en PetroAmerica plantean la integración de las empresas energéticas estatales de América Latina y del Caribe para la instrumentación de acuerdos y realizar inversiones conjuntas en la exploración, explotación y comercialización del petróleo y gas natural [...] Tales acciones se enmarcan en la actual política venezolana que apunta a favorecer a todos los países vecinos comprando en la región en vez de recurrir al 'primer mundo'.

A proposta venezuelana foi formulada, inicialmente, objetivando a fundação de uma empresa única, a qual congregaria as empresas estatais de hidrocarbonetos da região. À medida, porém, que as dificuldades para concretizar tais negociações se apresentaram, foram promovidas alterações nos mecanismos de integração, passando-se a priorizar, então, acordos de alcance sub-regional, cada um com características e especificidades próprias, as quais tornaram possível a efetivação das ações.

O primeiro passo nessa direção foi dado ainda em ig de outubro de 2000, quando, na cidade de Caracas, foi firmado o "Acuerdo de Cooperación Energética" (ACE). Naquela ocasião, representantes de Belize, Costa Rica, El Salvador, Guatemala, Honduras, Haiti, Jamaica, Nicarágua, Panamá, República Dominicana foram signatários de acordos bilaterais para a compra de hidrocarbonetos provenientes da Venezuela. Anunciou-se, ainda, a intenção de estender as condições acordadas a todos os demais países que a solicitassem e que, no juízo da diplomacia bolivariana, reunissem as características necessárias para figurarem como beneficiários da tratativa.

Por ela, estipulou-se a venda de petróleo bruto ou de subprodutos refi-

I7 O Acordo pode ser lido na íntegra em: http://www.sela.org/media/208769I/di-6-evolucion-petrocaribe-esp.pdf. 
nados com quinze anos de prazo para a amortização dos contratos de compra e venda, além de um período de carência de até um ano e taxa de juros não superiores a $2 \%$ ao ano. Nesse sentido, os dez acordos variavam, apenas, em relação ao volume de petróleo venezuelano disponível aos países, sendo este calculado em função das características, da estrutura energética e do consumo específicos de cada nação. As condições comerciais oferecidas pelos venezuelanos eram as mesmas para todos os compradores.

Ao referido conjunto de tratativas somou-se o "Convenio Integral de Cooperación" (CIC) firmado com Cuba, também no ano 2000. Enquanto este último ainda está vigente, o ACE foi absorvido pela iniciativa "PetroAmerica", a qual oferece condições comerciais ainda mais favoráveis para o intercâmbio petroleiro envolvendo as nações centro-americanas e caribenhas.

A partir de 2004, beneficiada pela estabilidade política interna, pela recuperação nos preços internacionais dos hidrocarbonetos e após a consolidação bem-sucedida do ACE, a diplomacia bolivariana passou a desfrutar de um cenário político-econômico favorável para investir ainda mais no aprofundamento de suas iniciativas internacionais. Assim, tendo como base a bonança petroleira e o "auge institucional" da Revolução Bolivariana - materializado pela conquista de todas as cadeiras do Congresso Nacional nas eleições legislativas de dezembro de 2005 - a postura então adotada pela PEB foi proativa ao fomentar a integração energética regional para, através dela, qualificar a participação do país no cenário interamericano.

Especificamente, como marco nesse reescalonamento da inserção internacional bolivariana, foram empreendidos importantes esforços no sentido de efetivar, na prática, o projeto "PetroAmerica". Como resultado de tal estratégia confluíram três iniciativas sub-regionais de integração energética: "PetroSur", "PetroAndina" e "PetroCaribe". Após uma década de atividades, tais projetos apresentaram resultados díspares. Enquanto os dois primeiros não avançaram de maneira satisfatória - por uma série de motivos, os quais foram expostos e problematizados em outro trabalho (Cicero 2015) - a "PetroCaribe" logrou relevantes conquistas, as quais serão brevemente expostas a seguir.

\section{“PetroCaribe”: integração energética e social}

A referida iniciativa, estabelecida em 29 de junho de 2005 por ocasião da assinatura do "Acuerdo de Cooperación Energética de Jefes de Estado y de Gobierno del Caribe ${ }^{18 ”}$, conta, até a presente data, com a participação dos 
seguintes Estados: Antígua e Barbuda, Bahamas, Belize, Dominica, Granada, Guatemala, Guiana, Haiti, Honduras, Jamaica, Nicarágua, República Dominicana, São Cristóvão e Neves, São Vicente e Granadinas, Santa Lúcia e Suriname. A ação é concebida como uma incubadora de políticas e projetos vinculados ao setor energético, a qual almeja promover a integração dos países centro-americanos e caribenhos tanto mediante o uso dos recursos naturais, quanto através da coordenação política das relações entre seus membros.

Em linhas gerais, o principal objetivo que levou à integração entre as referidas nações foi a intenção de articular as políticas públicas relacionadas à questão energética para facilitar a complementaridade comercial e o estreitamento político entre o grupo. Para tanto, a proposta pauta-se em dois pilares fundamentais: primeiro, na solidariedade de um Estado superavitário em energia - a Venezuela - com países de escassas fontes e recursos energéticos; e, segundo, no reconhecimento das assimetrias entre os níveis de desenvolvimento econômico apresentados pelas nações envolvidas e a intenção de mitigá-los (Girvan 2008).

Almeja-se, pois, impulsionar a integração regional pautada nos princípios da união, cooperação, complementaridade e no desenvolvimento socioeconômico. A partir de tais bases, o governo bolivariano, nos primeiros dez anos de atividades da PetroCaribe, estimou que tenha financiado o montante de 200 mil barris diários de combustíveis no âmbito da iniciativa, quantidade esta que, sozinha, superou significativamente a cooperação ofertada pelos países desenvolvidos nos marcos dos Objetivos do Milênio propostos pelas Nações Unidas (Ruiz-Caro 2006).

Nesse sentido, o projeto "PetroCaribe" concretizou as inovações propugnadas pela PEB em matéria de cooperação energética, na medida em que extrapolou-se a esfera estritamente comercial para incluir em seu rol de competências ações tais como: a planificação da política energética dos países membros, desde a exploração dos hidrocarbonetos nas jazidas disponíveis até ao transporte ao mercado consumidor; a construção de novas plantas para refinar e armazenar o combustível; instar o desenvolvimento da indústria petroquímica e financiar a capacitação e a assistência tecnológica necessárias para se garantir a eficiência da atividade comercial; articular e promover o estabelecimento de empresas estatais de energia nos países onde estas não existam ${ }^{\text {I9 }}$.

Respeitando, portanto, a mesma lógica integracionista proposta sob o projeto "guarda-chuva" PetroAmerica, a iniciativa caribenha caracteriza-se por

attach/258/EDOCS/SRed/2013/09/T023600Di_No._3_Acuerdo_de_Cooperacion_ PETROCARIBE-Final_doc_Rev_21-8-13.pdf.

I9 Objetivos estes expressos no Acordo de Cooperação retromencionado. 
ir além da fundamentação exclusivamente comercial. Esta particularidade, porém, não anula os atrativos ofertados nessa seara, na medida em que a PetroCaribe possibilita aos países importadores do combustível venezuelano diversas vantagens econômicas. Entre outros benefícios, o acordo assevera aos primeiros um período de carência de até dois anos para efetuar o pagamento do seu consumo de hidrocarbonetos, bem como expressa o compromisso venezuelano em arcar unilateralmente com os custos da instalação da infraestrutura necessária para efetivar e qualificar a prática comercial através, por exemplo, da construção de refinarias em Cuba e na Jamaica.

Ademais, com o fim de operacionalizar o acordo PetroCaribe, a petroleira estatal venezuelana PDVSA fundou uma empresa filial, denominada PDV Caribe S.A. As atividades desempenhadas pela companhia são voltadas à materialização dos contratos e da logística de suporte necessários para a realização da iniciativa de integração regional. Sobre os propósitos da nova empresa, complementa Jácome (20II, 05):

En la actualidad Pdvsa vende el crudo y sus derivados a crédito y los países receptores tienen hasta 25 años para pagar, con un tasa de interés de $2 \%$ si el barril está en menos de \$ 40 dólares y I\% si sobrepasa esa cifra. Los signatarios reciben los productos con un financiamiento de $40 \%$ cuando el precio sobrepasa los 50 dólares, $50 \%$ si está por encima de 80 y $60 \%$ cuando llega a ıoo dólares o más.

Ou seja, tendo em vista tais condições, não causou surpresa a declaração de Óscar Arias, então presidente da Costa Rica, o qual, por ocasião das negociações [não bem-sucedidas] voltadas à inclusão do país centro-americano no PetroCaribe, declarou publicamente em uma visita oficial à União Europeia que os créditos e recursos destinados à cooperação proporcionados pelos venezuelanos para a região somavam o quádruplo do montante oferecido pelos estadunidenses. Ademais, tendo como base os cálculos efetuados pelo FMI, em países como Guiana, Jamaica e Nicarágua, o volume de financiamento obtido através dos programas vinculados ao PetroCaribe equivaliam a algo entre $4 \%$ e $5 \%$ do PIB dessas nações (Altmann 2009).

Assim, no que concerne especificamente à política de integração energética fomentada pelo país, o ano de 2007 foi especialmente proveitoso, tendo em vista o fato dos membros da PetroCaribe concluírem negociações que não só reafirmaram os esforços pela integração energética entre os Estados signatários como, também, ampliaram seu escopo de atuação em direção ao princípio do desenvolvimento social. Para tanto, entre outras deliberações, formalizou-se o entendimento segundo o qual a iniciativa deveria transcender o âmbito energético para colocar-se nos espaços de integração produtiva e de de- 
senvolvimento social através de ações tais como: o estabelecimento de acordos de compra de produtos originários dos países de menor desenvolvimento relativo (produção avícola, pesca, de açúcar e de banana, entre outros) pelos países de maior desenvolvimento relativo; a construção de infraestrutura hoteleira para a exploração conjunta do turismo; a articulação e a instrumentalização de programas sociais comuns para aperfeiçoar seu impacto, bem como o desenvolvimento conjunto do transporte aéreo e marítimo como requisito indispensável para a efetivação da integração ${ }^{20}$.

\section{Considerações Finais}

Tendo em vista a argumentação aqui apresentada - a qual buscou retratar, fundamentalmente, os impactos oriundos do comércio internacional de hidrocarbonetos na articulação e na prática da política externa desempenhada ao longo dos dois primeiros mandatos cumpridos por Hugo Chávez - é possível identificar nesta um padrão de comportamento relativamente estável, qual seja, a utilização da chamada "diplomacia do petróleo" como fomentadora de uma proposta integracionista que destoou daquela praticada ao longo do período de hegemonia neoliberal em nossa região. No mesmo sentido, o presente estudo enfatiza que, dada sua estrutura econômica rentista, o país dispõe de uma posição pronunciadamente instável no contexto das relações econômicas internacionais hodiernas, na medida em que suas forças e debilidades estão, majoritariamente, atreladas aos, ora expressivos, ora insuficientes, recursos obtidos com a venda de petróleo.

Assim, se no âmbito interno o governo bolivariano não logrou reunir as condições necessárias para desmantelar a rede comandada pelas empresas transnacionais envolvidas na exploração dos hidrocarbonetos venezuelanos (Cicero 20I5), Chávez e seus correligionários dispuseram de uma margem de manobra um pouco mais ampla, porém limitada, ao tomarem parte na política internacional. Nessa lógica, durante os não raros períodos de bonança (notadamente no início do mandato, através da rearticulação da OPEP, e durante boa parte de seu segundo termo presidencial) a Venezuela, mais uma vez em sua história recente, colocou em prática a "diplomacia do petróleo" para aumentar e qualificar sua inserção político-econômica nas relações internacionais.

Por conseguinte, ao lançar mão do projeto "PetroAmerica" - uma ambiciosa iniciativa de integração energética regional, a qual se encontra bem-articulada à proposta inovadora encampada pela ALBA - a PEB, avalizada pelos

20 A declaração onde tais propostas estão positivadas está disponível em: http://www.granma. $\mathrm{cu} /$ granmad/secciones/petrocaribe/cumbres-cel/acuerdo-3.html. 
petrodólares, avançou significativamente em ampliar sua presença comercial e seu peso político nas relações interamericanas. Estabeleceu-se, pois, uma limitada, porém relevante, contribuição dos bolivarianos para o arrefecimento da hegemonia estadunidense e, conseqüentemente, para a tentativa de promover a rearticulação multipolar das relações de poder no Sistema Internacional.

Em contrapartida, mesmo nesses momentos - e ainda mais naqueles em que o preço do petróleo esteve em queda, como ocorreu, por exemplo, a partir de 2009 - a capacidade de qualificar e expandir de maneira sustentada a inserção internacional da proposta bolivariana esteve mitigada pelas amarras político-econômicas impostas a um país periférico como a Venezuela no contexto da divisão internacional do trabalho.

\section{REFERÊNCIAS}

Alfonso, H.D. 2006. Hugo Chávez y Cuba: subsidiando posposiciones fatales. Nueva Sociedad, $\mathrm{n}^{0}$ 205, I4I-I58.

Altmann, J. 2009. ALBA: institutions and mechanisms. Quito: Publicaciones de La Secretaria General de FLACSO.

Arriagada, G. 2005. Petróleo y gas en América Latina: un análisis político y de relaciones internacionales a partir de la política venezolana. Real Instituto Elcano de Estudios Internacionales y Estratégicos, n. 20, OI-35.

Benzi, D. e Zapata, X. 20I3. Geopolítica, economía y solidaridad internacional en la nueva cooperación Sur-Sur: el caso de la Venezuela bolivariana y petrocaribe. América Latina Hoy, (63): 65-89.

Boersner, D. 2009. Incidencia internacional de la política exterior venezolana. Nueva Economía, (I7) 29: 35-73.

Cicero, P.H.M. 20I5. O rentismo petroleiro e suas implicações para a política externa venezuelana. Tese de doutorado. Campinas: Universidade Estadual de Campinas.

Danese, S. I999. Diplomacia Presidencial. Rio de Janeiro: Topbooks.

Fuser, I. 20II. Segurança energética, nacionalismo de recursos e integração na América do Sul. Seminário Discente FFLCH/USP. Disponível em: [http://www.fflch.usp.br/dcp/assets/docs/SemDisc2oII/Sessao_IX_ Fuser.pdf]. Acesso em: 30 nov. 20I5.

Girvan, N. 2008. ALBA, PETROCARIBE and CARICOM: issues in a new dynamic. Disponível em: [http://www.normangirvan.info/girvan-al- 
ba-caricom-mayo]. Acesso em: 30 nov. 2015.

González, M. 2003. El petróleo como instrumento de política exterior en el gobierno del presidente Hugo Chávez Frías. Revista Venezolana de Análisis de Coyuntura, vol. IX, (2): 59-87.

Hidalgo, M. 2009. Hugo Chavez's "Petro-Socialism”. Journal of Democracy, (20)2: 78-92.

Illera, O. 2005. La política exterior de Chávez: proyección de la Revolución Bolivariana en las Relaciones Internacionales. Revista Desafíos, (I2): 209-240.

Jácome, F. 20II. Petrocaribe: la fase actualde la diplomacia petrolera venezolana en el Caribe. Friedrich Ebert Stiftung Policy Paper. Disponível em: [http://library.fes.de/pdf-files/bueros/la-seguridad/o8722.pdf]. Acesso em: 30.nov. 2015 .

Lander, L. 2005. Petróleo y democracia en Venezuela: del fortalecimiento del Estado a la subversión soterrada y la insurrección abierta. Revista Galega de Economia, (I4,) I-2: OI-I4.

Mayobre, E. 2005. La propuesta de Petroamérica y la Integración Energética de América Latina y el Caribe. Caracas: ILDIS.

Miranda, J.A.A. 20I2. A política externa da Venezuela no governo Hugo Chávez Frías: atores civis e militares. Tese de Doutorado. Porto Alegre: Universidade Federal do Rio Grande do Sul.

Poertner, M. 20II. Venezuela Oil Diplomacy and Voting in the U.N. General Assembly. Journal of International Service, (20)1: 85-108.

Romero, C.A. 2006. Venezuela y Estados Unidos: cuna relación esquizofrénica? Nueva Sociedad, n. 206, p.78-93.

20Io. A política externa da Venezuela bolivariana. Plataforma Democrática, (4):02-36.

Ruíz-Caro, A. 2006. Cooperación e integración energética en América Latina y el Caribe. Santiago: División de Recursos Naturales e Infraestructura, CEPAL.

Smith, S; Hadfield, A. e Dunnet. 2008. Foreign Policy: Theories, Actors, Cases. New York: Oxford University Press.

Vera, L. 2005. Liderazgo Político, Renta y Política Económica: la gestión económica en la era Chávez. Caracas: Universidad Central de Venezuela.

Villa, R.D. A política externa venezuelana de Chávez para a América do Sul: entre a ideologização das identidades e as necessidades do pragmatismo. Observatório Político Sul-Americano, Análise de conjuntura, (Io): $35-49$. 


\section{RESUMO}

O artigo investiga, em três etapas, a política externa venezuelana exercida entre I999 e 2007. Inicialmente, aportaram-se esforços para o fortalecimento da OPEP. Já entre $200 \mathrm{I}$ e 2003 , a crise política interna repercutiu negativamente na inserção internacional almejada pelos venezuelanos. Por fim, entre 2004 e 2007 , a postura proativa inicial foi retomada com base na "diplomacia do petróleo".

\section{PALAVRAS-CHAVE}

Política Externa; Venezuela; Petróleo.

Recebido em 4 de Abril de 2016. Aceito em 13 de Dezembro de 2016. 